Article

\title{
Development and Validation of an LC-MS/MS Method for Quantification of the Novel Antibacterial Candidate DA-7010 in Plasma and Application to a Preclinical Pharmacokinetic Study
}

\author{
Mi Hye Kwon ${ }^{1,2}$, Dae Young Lee ${ }^{3}$ and Hee Eun Kang ${ }^{1, *(\mathbb{D}}$ \\ 1 College of Pharmacy and Integrated Research Institute of Pharmaceutical Sciences, \\ The Catholic University of Korea, Bucheon 14662, Korea; kwonmh@kirams.re.kr \\ Korea Institute of Radiological \& Medical Sciences, Seoul 01812, Korea \\ 3 Research Center, Dong-A ST Co. Ltd., Yongin 17073, Korea; dylee@donga.co.kr \\ * Correspondence: kanghe@catholic.ac.kr; Tel.: +82-2-2164-4055
}

Citation: Kwon, M.H.; Lee, D.Y.; Kang, H.E. Development and Validation of an LC-MS/MS Method for Quantification of the Novel Antibacterial Candidate DA-7010 in Plasma and Application to a Preclinical Pharmacokinetic Study. Pharmaceuticals 2021, 14, 163. https://doi.org/10.3390/ph14020163

Academic Editor: Luisa Barreiros

Received: 21 January 2021

Accepted: 16 February 2021

Published: 18 February 2021

Publisher's Note: MDPI stays neutral with regard to jurisdictional claims in published maps and institutional affiliations.

Copyright: (c) 2021 by the authors. Licensee MDPI, Basel, Switzerland. This article is an open access article distributed under the terms and conditions of the Creative Commons Attribution (CC BY) license (https:// creativecommons.org/licenses/by/ $4.0 /)$.

\begin{abstract}
DA-7010 is a new candidate for an antibacterial agent that targets Gram-negative pathogens by acting as a leucyl-tRNA synthetase inhibitor. In this study, a simple and rapid liquid chromatography tandem mass spectrometry (LC-MS/MS) method was developed to determine DA-7010 levels in the plasma from mice, rats, and dogs. Plasma samples were mixed with methanol for protein precipitation. Chromatographic separation was carried out using a reversed-phase $\mathrm{C}_{18}$ column (Agilent Poroshell 120, $50 \times 3.0 \mathrm{~mm}, 2.7 \mu \mathrm{m}$ ). An isocratic elution of the mobile phase consisting of $5 \mathrm{mM}$ formic acid in water and acetonitrile at a ratio of 84:16 $(v / v)$ was applied at a flow rate of $0.3 \mathrm{~mL} / \mathrm{min}$. The total chromatographic run time was $3.5 \mathrm{~min}$. Multiple reaction monitoring (MRM) mode was used for mass spectrometric detection using an Agilent 6460 triple quadrupole coupled with an electrospray ionization (ESI) source operated in positive-ion mode. The MRM transitions analyzed were $m / z 220.1 \rightarrow 162.1$ for DA-7010 and $m / z 206.1 \rightarrow 170.1$ for the internal standard (structural analogue of DA-7010). Calibration curves were constructed in the range of 10-10,000 ng/mL. The intra- and interday precision and accuracy were within $11.3 \%$, excluding those for the lower limit of quantification (LLOQ) samples, which were within 17.1\%. The developed LC-MS/MS method was successfully validated and applied in preclinical pharmacokinetic studies of DA-7010 in mice, rats, and dogs following single oral administrations. The oral absorption of DA-7010 was rapid, and the systemic exposure was approximately four times higher in the dogs than in the mice or rats.
\end{abstract}

Keywords: DA-7010; LC-MS/MS; mouse; rat; dog; plasma; pharmacokinetics

\section{Introduction}

Infections of carbapenem-resistant or multidrug-resistant Gram-negative pathogens are major healthcare concerns due to high morbidity and the absence of new drug development [1]. DA-7010 (((2S,7R)-7-methyl-7,8-dihydro-2H-1,6,9-trioxa-9a-borabenzo[cd]azulen2-yl)methanamine; Figure 1a; confirmed by HR-MS and ${ }^{1} \mathrm{H}-\mathrm{NMR}$ spectra (Figure S1)) is a new candidate for an antibacterial agent against Gram-negative pathogens due to acting as a leucyl-tRNA synthetase (LeuRS) inhibitor with a tricyclic benzoxaborole moiety [2,3]. In the past decade, benzoxaborole moieties have been applied in the design of various compounds for antimicrobial and anti-inflammatory agents due to their drugability [4]. A subset of benzoxaboroles inhibit LeuRS through an oxaborole tRNA-trapping mechanism, which forms a stable leucyl-tRNA-benzoxaborole adduct [5]. Because the structures of aminoacyl-tRNA synthetases (ARSs) found in eukaryotes have considerable structural differences from those in prokaryotes, it is possible to develop highly selective inhibitors that can achieve antibacterial-specific responses [6]. Apart from translation, emerging roles of host ARSs have been identified in anti-infectious signaling and antimicrobial immunity $[7,8]$. In recent years, basic and clinical studies have been underway to apply 
therapeutics based on ARS inhibition to various diseases such as neurological disorders, fibrosis, and cancer as well as infectious diseases [9-11].

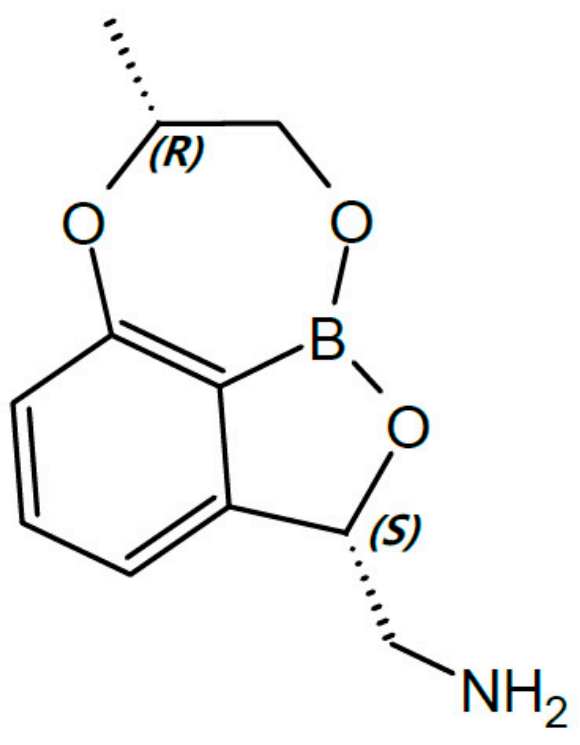

(a)

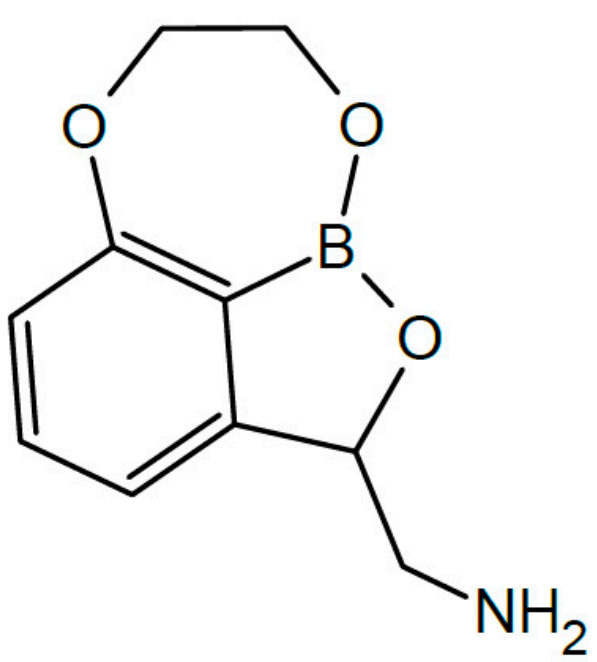

(b)

Figure 1. Chemical structures of DA-7010 and the internal standard (IS): (a) DA-7010; (b) the IS.

DA-7010 showed excellent in vitro and in vivo antibacterial efficacy, with a minimum inhibitory concentration (MIC) of $0.25-2 \mu \mathrm{g} / \mathrm{mL}$ for DA-7010 against Gram-negative bacteria (except for Pseudomonas aeruginosa) and effective oral doses of $1.9-3 \mathrm{mg} / \mathrm{kg}$ that protected $50 \%$ of mice systemically infected with carbapenem-resistant Acinetobacter baumannii $\left(\mathrm{ED}_{50}\right)[2,3]$. Pharmacokinetic studies of DA-7010 in experimental animals are essential for the further development of DA-7010 as an antibacterial agent. The preclinical pharmacokinetic characterization of DA-7010 is required for a comprehensive understanding of its efficacy and potential toxicity. For pharmacokinetic studies of DA-7010 to be successful in various species of animals, efficient and robust quantitative methods for determining DA-7010 in biological fluids are essential.

In this study, a simple LC-MS/MS method for the robust and accurate determination of DA-7010 in plasma from mice, rats, and dogs was developed and validated. The method was optimized to realize the precise and accurate quantification of DA-7010 in plasma samples from various animal species. Pharmacokinetic studies of DA-7010 following a single oral administration to mice, rats, and dogs were performed using the proposed method.

\section{Results and Discussion}

\subsection{Development of Analytical Method}

We optimized the instrumental parameters for mass spectrometry to obtain sensitive and robust signals for the analyte. The internal standard (IS) for the DA-7010 analysis, 7,8dihydro-2H-1,6,9-trioxa-9a-borabenzo[cd]azulen-2-yl)methanamine (a DA-7010 analogue; Figure 1b), was chosen for its structural similarity to DA-7010. Full-scan mass spectra (Figure S2) and product ion spectra of DA-7010 and the IS (Figure 2) were obtained in positive electrospray ionization (ESI) mode. For the quantification of DA-7010, one selected precursor-to-product ion transition of $m / z 220.1\left([\mathrm{M}+\mathrm{H}]^{+}\right) \rightarrow 162.1\left(\right.$ loss of $\left.\mathrm{C}_{3} \mathrm{H}_{6} \mathrm{O}\right)$ was monitored. The transition selected and monitored for the IS was $m / z 206.1\left([\mathrm{M}+\mathrm{H}]^{+}\right) \rightarrow 170.1$ (loss of $2 \mathrm{H}_{2} \mathrm{O}$ ). 
(a)
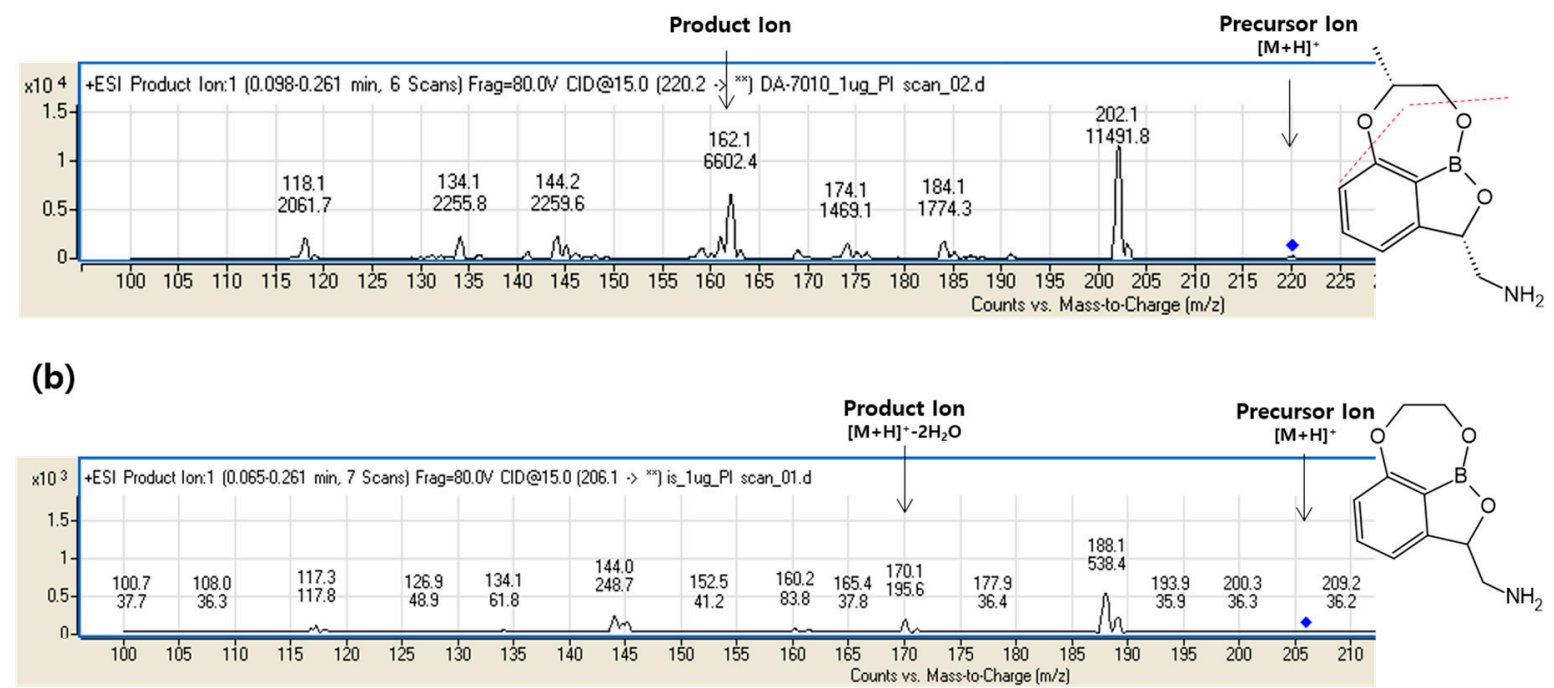

Figure 2. Product ion mass spectra of (a) DA-7010 and (b) the IS.

The chromatographic conditions were optimized with a reversed-phase HPLC Poroshell $120 \mathrm{C}_{18}$ column $(50 \mathrm{~mm} \mathrm{~L} . \times 3.0 \mathrm{~mm}$ i.d.; particle size, $2.7 \mu \mathrm{m})$ that provided excellent resolution and peak symmetry. An isocratic elution of $5 \mathrm{mM}$ formic acid in water (A) and acetonitrile $(\mathrm{B})(\mathrm{A}: \mathrm{B}=84: 16(\mathrm{v} / \mathrm{v}))$ resulted in optimum retention times for the analyte and IS and the avoidance of the matrix effect for DA-7010. An acceptable peak shape and resolution along with an adequate retention time were achieved for the analyte in this optimized chromatographic condition. The total chromatographic run time for each was $3.5 \mathrm{~min}$, which was highly efficient. The retention times of DA-7010 and the IS were approximately 1.8 and $1.2 \mathrm{~min}$, respectively.

Protein precipitation methods were initially attempted for sample preparation because of their simplicity. Sufficient and reproducible recoveries of DA-7010 and the IS were achievable by simple protein precipitation using methanol.

\subsection{Validation of Analytical Method}

\subsubsection{Selectivity and Carryover}

Representative chromatograms of blank mouse, rat, and dog plasma are presented (Figure 3a), as well as plasma spiked with DA-7010 at the lower limit of quantification (LLOQ) level and the IS (Figure 3b). The chromatograms for plasma samples obtained $4 \mathrm{~h}$ after the oral administration of DA-7010 are presented in Figure 3c. No endogenous interference was observed at the retention times for DA-7010 or the IS, indicating that the developed method was specific. No carryover was found under the conditions used, as observable by the absence of a significant peak ( $\geq 20 \%$ of the LLOQ) of DA-7010 in a blank plasma sample analyzed right after the injection of a high quality control (QC) sample.

\subsubsection{Linearity and Sensitivity}

Calibration curves were generated using a weighted $\left(1 / x\right.$ or $\left.1 / x^{2}\right)$ least-squares linear regression plot of the peak area ratio of DA-7010 to the IS (y) versus the relative concentration of DA-7010 to the IS (x). The linearity of the calibration curves was observed over the DA-7010 concentration range of $10-10,000 \mathrm{ng} / \mathrm{mL}$ (Figure S3). The correlation coefficients $\left(r^{2}\right)$ of the calibration curves were $>0.995$. The typical regression equations of the calibration curves were as follows: $\mathrm{y}=1.5989 \mathrm{x}+0.0002938\left(r^{2}=0.9992\right)$ for the mouse plasma samples; $\mathrm{y}=2.7906 \mathrm{x}-0.0001545\left(r^{2}=0.9992\right)$ for the rat plasma samples; $\mathrm{y}=1.2445 \mathrm{x}+0.00001202\left(r^{2}=0.9951\right)$ for the dog plasma samples. The deviations of the back-calculated concentrations of the calibration samples from the nominal values were within the acceptable range ( $<15 \%$ except for the LLOQ level, $<20 \%$ ). The LLOQ for DA- 
7010 was confirmed as $10 \mathrm{ng} / \mathrm{mL}$ with a good signal-to-noise ratio $(>10)$ and acceptable accuracy $(80-120 \%)$ and precision (relative standard deviation (RSD) $<20 \%$ ). The developed method had enough sensitivity for determining DA-7010 plasma levels.

Mouse plasma

(a)
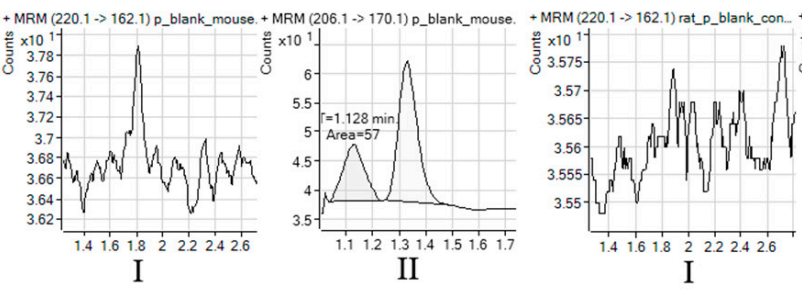

Rat plasma
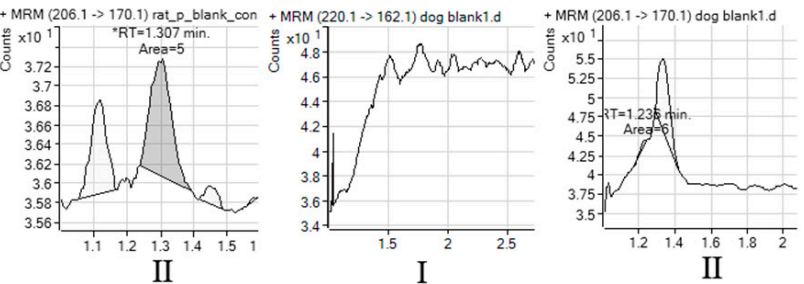

(b)

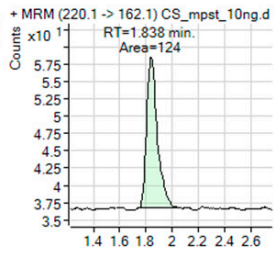

I

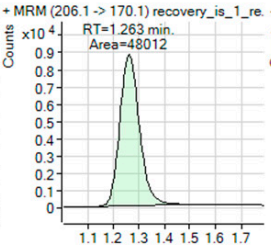

II

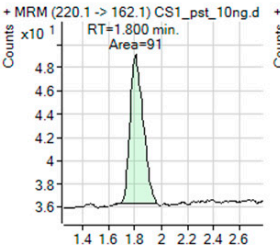

I
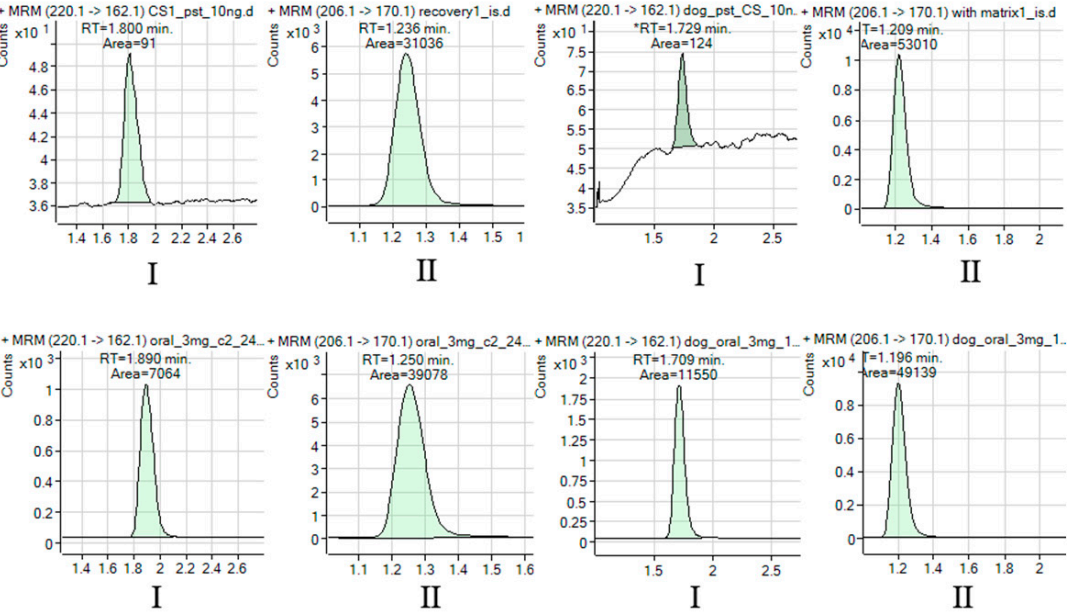

II

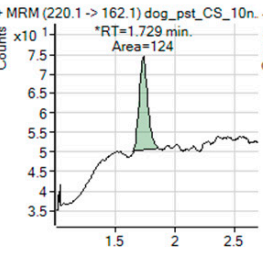

I

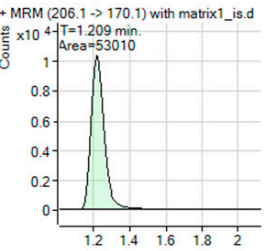

II (c)
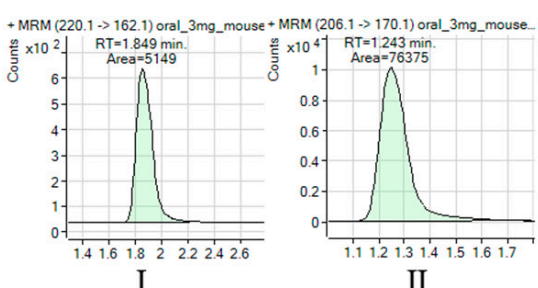

Figure 3. Representative multiple reaction monitoring (MRM) chromatograms of DA-7010 (I) and the IS (II) in each mouse, rat, and dog plasma sample: (a) blank plasma; (b) blank plasma spiked with lower limit of quantification (LLOQ) level of DA-7010 $(10 \mathrm{ng} / \mathrm{mL})$ or mixed with the IS at working concentrations $(10 \mu \mathrm{g} / \mathrm{mL})$; (c) plasma samples collected $4 \mathrm{~h}$ after oral administration of $3 \mathrm{mg} / \mathrm{kg}$ DA-7010 to mouse, rat, and dog with determined DA-7010 concentrations of 334, 648, and $1952 \mathrm{ng} / \mathrm{mL}$, respectively.

\subsubsection{Precision and Accuracy}

The intra- and interday precisions and accuracies for the analyses of QC samples with LLOQ, low, medium, and high concentrations of DA-7010 in mouse, rat, and dog plasma are presented in Table 1. The analytical precisions (expressed as RSDs) for the intraand interday analyses were within $11.3 \%$, except for the LLOQ (RSD $<17.1 \%)$. The intraand interday accuracies for the DA-7010 analyses in plasma from various species were $89.8-106 \%$, including for the LLOQ. These results demonstrate that the developed method had sufficient precision and accuracy for the quantification of DA-7010 in plasma from mice, rats, and dogs.

\subsubsection{Recovery and Matrix Effect}

The plasma samples were treated with methanol to precipitate the proteins and to achieve a reproducible recovery of DA-7010. The recovery and matrix effect are summarized in Table 2. The average recoveries of DA-7010 in the mouse, rat, and dog plasma after sample preparation were $86.2-93.6 \%, 69.5-80.2 \%$, and $74.3-83.2 \%$, respectively, and those for the IS were $87.4 \%, 84.9 \%$, and $93.5 \%$, respectively. Both DA-7010 and the IS showed consistent and reproducible recoveries (RSD $<13.8 \%$ ) from the plasma of all the tested species. The matrix effects of DA-7010 were within the range of $91.4-119 \%$, and the RSDs $(\%)$ from the six different plasma sources were $<8.04 \%$. These results indicate that interfer- 
ences from plasma matrix were adequately eliminated through proper sample preparation and chromatographic separation. Although matrix effects in the IS were observed in the mouse and rat plasma, an RSD $(\%)<4.20$ based on six different donors from each species ensured the robustness of the analytical method.

Table 1. Intra- and interday precision and accuracy of analysis for DA-7010 in mouse, rat, and dog plasma.

\begin{tabular}{|c|c|c|c|c|c|c|c|}
\hline \multirow[b]{2}{*}{ Matrix } & \multirow{2}{*}{$\begin{array}{c}\text { Nominal } \\
\text { Concentration } \\
(\mathrm{ng} / \mathrm{mL})\end{array}$} & \multicolumn{3}{|c|}{ Intraday $(n=5)$} & \multicolumn{3}{|c|}{ Interday $(n=5)$} \\
\hline & & $\begin{array}{c}\text { Calculated } \\
\text { Concentration } \\
(\text { Mean, ng/mL) }\end{array}$ & $\begin{array}{l}\text { Precision } \\
\text { (RSD, \%) }\end{array}$ & $\begin{array}{c}\text { Accuracy } \\
(\%)\end{array}$ & $\begin{array}{c}\text { Calculated } \\
\text { Concentration } \\
(\text { Mean, ng/mL) }\end{array}$ & $\begin{array}{l}\text { Precision } \\
\text { (RSD, \%) }\end{array}$ & $\begin{array}{c}\text { Accuracy } \\
(\%)\end{array}$ \\
\hline \multirow{4}{*}{ Mouse plasma } & 10 & 9.23 & 14.9 & 92.3 & 9.55 & 10.8 & 95.5 \\
\hline & 30 & 30.2 & 8.86 & 101 & 28.1 & 7.03 & 93.6 \\
\hline & 400 & 394 & 7.89 & 98.4 & 372 & 4.91 & 93.1 \\
\hline & 8000 & 7770 & 8.41 & 97.1 & 7760 & 11.3 & 97.0 \\
\hline \multirow{4}{*}{ Rat plasma } & 10 & 10.5 & 10.7 & 105 & 10.5 & 1.70 & 105 \\
\hline & 30 & 28.4 & 3.90 & 94.6 & 27.2 & 3.31 & 90.5 \\
\hline & 400 & 397 & 2.53 & 99.3 & 377 & 6.49 & 94.3 \\
\hline & 8000 & 8590 & 1.82 & 107 & 8240 & 8.45 & 103 \\
\hline \multirow{4}{*}{ Dog plasma } & 10 & 10.4 & 17.1 & 104 & 10.6 & 4.82 & 106 \\
\hline & 30 & 26.9 & 3.49 & 89.8 & 28.1 & 2.42 & 93.8 \\
\hline & 400 & 369 & 8.08 & 92.2 & 370 & 3.51 & 92.5 \\
\hline & 8000 & 7750 & 7.22 & 96.9 & 8330 & 6.76 & 104 \\
\hline
\end{tabular}

Table 2. Extraction recovery and matrix effect of DA-7010 and the IS in mouse, rat, and dog plasma.

\begin{tabular}{|c|c|c|c|c|c|}
\hline \multirow{2}{*}{ Matrix/Analytes } & \multirow{2}{*}{ Nominal Concentration (ng/mL) } & \multicolumn{2}{|c|}{ Recovery $(n=5)$} & \multicolumn{2}{|c|}{ Matrix Effect $(n=6)$} \\
\hline & & Mean \pm SD (\%) & RSD (\%) & Mean \pm SD (\%) & RSD (\%) \\
\hline \multicolumn{6}{|l|}{ Mouse plasma } \\
\hline \multirow[t]{3}{*}{ DA-7010 } & 30 & $93.6 \pm 5.99$ & 6.40 & $95.5 \pm 5.69$ & 5.96 \\
\hline & 400 & $86.2 \pm 1.00$ & 11.6 & $96.4 \pm 7.75$ & 8.04 \\
\hline & 8000 & $88.9 \pm 12.2$ & 13.8 & $97.1 \pm 3.50$ & 3.61 \\
\hline IS & 10,000 & $87.4 \pm 1.22$ & 1.40 & $71.1 \pm 2.09$ & 2.94 \\
\hline \multicolumn{6}{|l|}{ Rat plasma } \\
\hline \multirow[t]{3}{*}{ DA-7010 } & 30 & $69.5 \pm 1.88$ & 2.72 & $103 \pm 4.95$ & 4.81 \\
\hline & 400 & $69.7 \pm 3.44$ & 4.93 & $91.4 \pm 4.67$ & 5.11 \\
\hline & 8000 & $80.2 \pm 1.78$ & 2.21 & $98.2 \pm 2.45$ & 2.50 \\
\hline IS & 10,000 & $84.9 \pm 2.49$ & 2.93 & $50.8 \pm 2.13$ & 4.20 \\
\hline \multicolumn{6}{|l|}{ Dog plasma } \\
\hline \multirow[t]{3}{*}{ DA-7010 } & 30 & $83.2 \pm 4.96$ & 5.96 & $119 \pm 8.30$ & 6.99 \\
\hline & 400 & $74.5 \pm 4.78$ & 6.42 & $103 \pm 3.87$ & 3.76 \\
\hline & 8000 & $74.3 \pm 2.50$ & 3.36 & $94.3 \pm 2.32$ & 2.46 \\
\hline IS & 10,000 & $93.5 \pm 4.18$ & 4.47 & $95.7 \pm 3.03$ & 3.17 \\
\hline
\end{tabular}

\subsubsection{Stability of the Analyte}

Table 3 summarizes the stability of DA-7010 in the plasma from each species evaluated by analyzing three replicates of QC samples (low, medium, and high concentrations) under various storage conditions. DA-7010 was stable (mean recoveries $>85.5 \%$ ) for at least $8 \mathrm{~h}$ at room temperature, $24 \mathrm{~h}$ when kept in an LC vial at $4{ }^{\circ} \mathrm{C}$ after sample preparation, and 1 month when stored at $-20^{\circ} \mathrm{C}$. The analyte was stable even after three freeze/thaw $\left(-20^{\circ} \mathrm{C} /\right.$ room temperature) cycles (mean recoveries $>87.7 \%$ ). Therefore, DA-7010 is stable during sample storage, preparation, and analysis (in the plasma of the species analyzed).

\subsection{Application in Pharmacokinetic Studies}

The validated LC-MS/MS method was applied to pharmacokinetic studies of DA7010 after administration of a single oral dose $(3 \mathrm{mg} / \mathrm{kg})$ of DA-7010 to mice, rats, and dogs. It should be noted that this oral dose has been found to be an $\mathrm{ED}_{50}$ in mice with systemic infection. The profiles of the mean plasma concentration of DA-7010 versus time 
are presented in Figure 4. The developed method proved to have enough sensitivity for the quantification of DA-7010 for up to 10,12, and $24 \mathrm{~h}$ in the mouse, rat, and dog plasma samples, respectively. The pharmacokinetic parameters of DA-7010 in the mice, rats, and dogs are summarized in Table 4 . The total area under the plasma concentration-time curve from time zero to infinity $\left(\mathrm{AUC}_{0-\infty}\right)$ of DA-7010 in the dogs was much greater than those in the mice or rats. The maximum plasma concentration $\left(C_{\max }\right)$ values for the studied animal species were similar to the reported MICs for DA-7010, $0.25-2 \mu \mathrm{g} / \mathrm{mL}[2,3]$. In the mice and rats, the absorption of DA-7010 was rapid in view of the fast time to reach $C_{\max }\left(T_{\max }\right)$. Considering the dissolution time for DA-7010 in the gelatin capsule, it was also rapidly absorbed in dogs.

Table 3. Stability ( $\%$ recovery, $n=3$ ) of DA-7010 in mouse, rat, and dog plasma under various storage conditions.

\begin{tabular}{|c|c|c|c|c|c|c|c|}
\hline \multirow[b]{2}{*}{ Storage Conditions } & \multirow{2}{*}{$\begin{array}{c}\text { Nominal } \\
\text { Concentration } \\
(\mathrm{ng} / \mathrm{mL})\end{array}$} & \multicolumn{2}{|c|}{ Mouse Plasma } & \multicolumn{2}{|c|}{ Rat Plasma } & \multicolumn{2}{|c|}{ Dog Plasma } \\
\hline & & $\begin{array}{c}\text { Mean } \pm \text { SD } \\
(\%)\end{array}$ & $\begin{array}{c}\text { RSD } \\
(\%)\end{array}$ & $\begin{array}{c}\text { Mean } \pm \text { SD } \\
(\%)\end{array}$ & $\begin{array}{c}\text { RSD } \\
(\%)\end{array}$ & $\begin{array}{c}\text { Mean } \pm \text { SD } \\
(\%)\end{array}$ & $\begin{array}{l}\text { RSD } \\
(\%)\end{array}$ \\
\hline \multirow[t]{3}{*}{ Short term ${ }^{1}$} & 30 & $109 \pm 4.97$ & 4.54 & $110 \pm 4.64$ & 4.21 & $107 \pm 3.08$ & 2.88 \\
\hline & 400 & $97.5 \pm 6.48$ & 6.65 & $97.9 \pm 0.394$ & 0.403 & $92.9 \pm 1.62$ & 1.74 \\
\hline & 8000 & $89.0 \pm 2.24$ & 2.51 & $104 \pm 0.647$ & 0.623 & $108 \pm 1.22$ & 1.12 \\
\hline \multirow[t]{3}{*}{ Post-preparative ${ }^{2}$} & 30 & $106 \pm 5.14$ & 4.86 & $95.5 \pm 3.65$ & 3.82 & $110 \pm 5.48$ & 4.98 \\
\hline & 400 & $92.7 \pm 2.58$ & 2.78 & $101 \pm 1.33$ & 1.32 & $108 \pm 1.72$ & 1.59 \\
\hline & 8000 & $89.9 \pm 7.84$ & 8.73 & $111 \pm 4.06$ & 3.65 & $116 \pm 2.34$ & 2.02 \\
\hline \multirow[t]{3}{*}{ Freeze-thaw $^{3}$} & 30 & $109 \pm 6.63$ & 6.10 & $107 \pm 5.92$ & 5.50 & $110 \pm 3.32$ & 3.01 \\
\hline & 400 & $91.2 \pm 2.22$ & 2.43 & $94.8 \pm 6.20$ & 6.54 & $107 \pm 2.01$ & 1.89 \\
\hline & 8000 & $87.7 \pm 2.58$ & 2.95 & $100 \pm 0.407$ & 0.406 & $114 \pm 0.0718$ & 0.0628 \\
\hline \multirow[t]{3}{*}{ Long term ${ }^{4}$} & 30 & $106 \pm 1.54$ & 1.46 & $85.5 \pm 0.618$ & 0.722 & $113 \pm 0.500$ & 0.442 \\
\hline & 400 & $95.5 \pm 3.04$ & 3.19 & $95.2 \pm 3.30$ & 3.47 & $97.3 \pm 1.22$ & 1.25 \\
\hline & 8000 & $88.5 \pm 1.77$ & 2.00 & $107 \pm 2.67$ & 2.49 & $111 \pm 3.13$ & 2.82 \\
\hline
\end{tabular}

${ }^{1}$ Storage at room temperature for $8 \mathrm{~h} ;{ }^{2}$ Storage of prepared samples at $4{ }^{\circ} \mathrm{C}$ for $24 \mathrm{~h} ;{ }^{3}$ Storage after 3 freeze/thaw $\left(-20{ }^{\circ} \mathrm{C} /\right.$ room temperature) cycles; 4 Storage at $-20{ }^{\circ} \mathrm{C}$ over 1 month.

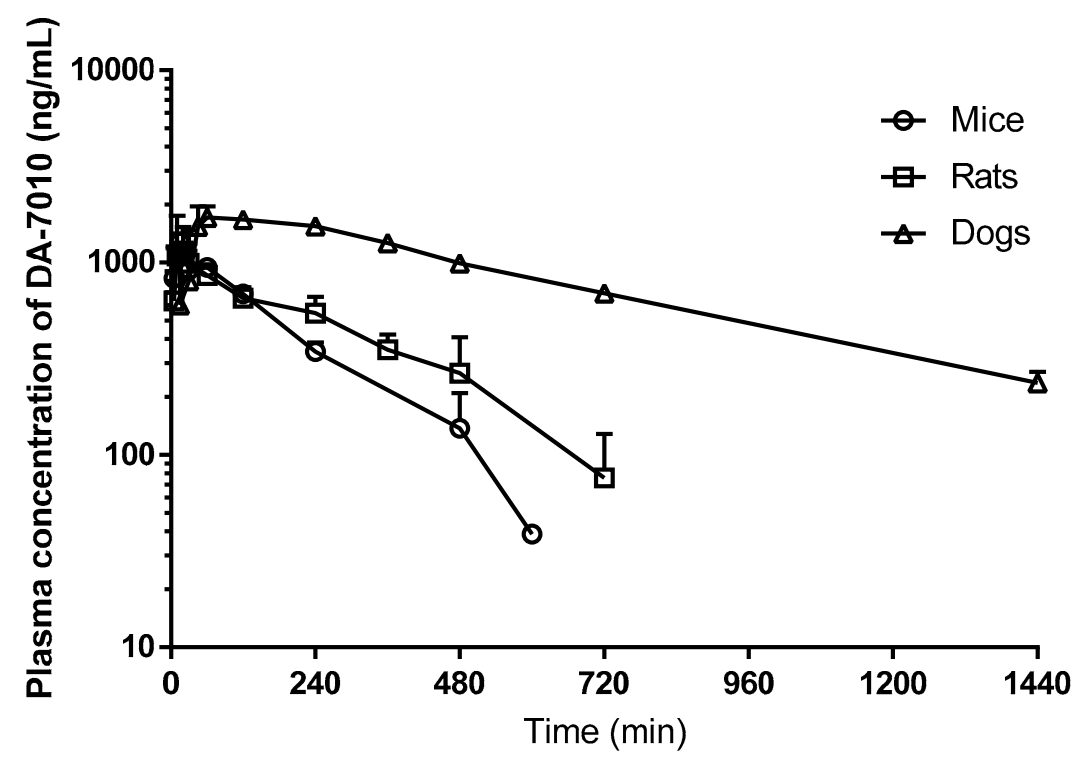

Figure 4. Mean arterial plasma concentration-time profiles of DA-7010 following oral administration of DA-7010 at a dose of $3 \mathrm{mg} / \mathrm{kg}$ to mice ( $n=6$ for each point), rats $(n=7)$, and dogs $(n=4)$. Data are expressed as mean $\pm \mathrm{SD}$. 
Table 4. Pharmacokinetic parameters for DA-7010 after single oral administration at a dose of 3 $\mathrm{mg} / \mathrm{kg}$ to mice, rats, and dogs.

\begin{tabular}{cccc}
\hline Parameters & $\begin{array}{c}\text { Mice } \\
(\boldsymbol{n}=\mathbf{6} \text { for Each Data Point })^{\mathbf{3}}\end{array}$ & $\begin{array}{c}\text { Rats } \\
(\boldsymbol{n}=\mathbf{7})\end{array}$ & $\begin{array}{c}\text { Dogs } \\
(\boldsymbol{n}=\mathbf{4})\end{array}$ \\
\hline Body weight $(\mathrm{kg})$ & $0.0246 \pm 0.000965$ & $0.242 \pm 0.00393$ & $9.47 \pm 0.738$ \\
$\mathrm{AUC}_{0-\infty}(\boldsymbol{\mu} \cdot \mathrm{g} \cdot \mathrm{min} / \mathrm{mL})^{1}$ & 235 & $319 \pm 45.5$ & $1310 \pm 95.7$ \\
$\mathrm{Terminal} \mathrm{half-life}(\mathrm{min})_{C_{\max }(\mu \mathrm{g} / \mathrm{mL})}^{125}$ & 1.28 & $173 \pm 48.6$ & $452 \pm 33.8$ \\
$T_{\max }(\mathrm{min})^{2}$ & 15 & $1.33 \pm 0.427$ & $1.82 \pm 0.0901$ \\
\hline
\end{tabular}

${ }^{1}$ Total area under the plasma concentration-time curve from time zero to infinity. ${ }^{2} T_{\max }$ is expressed as median (range). ${ }^{3}$ Pharmacokinetic parameters were obtained from a mean concentration-time profile.

\section{Materials and Methods}

\subsection{Chemicals and Reagents}

The DA-7010 hydrochloride (purity, 99.5\%; batch no. R-K-14001) and the IS for the DA-7010 analysis (purity, 96.4\%) were products of Dong-A ST (Yongin, South Korea). The other solvents and chemicals were either HPLC or reagent grade.

\subsection{Instrumental Conditions for LC-MS/MS}

The instrumental system for LC-MS/MS consisted of an Agilent 1260 LC system and an Agilent 6460 triple quadrupole tandem mass spectrometer (Agilent, Waldbronn, Germany). The instrument control, data acquisition, and processing of the data were conducted using the Agilent Mass Hunter Workstation software (ver. B.04.01).

A reversed-phase HPLC column (Agilent Poroshell $120 \mathrm{C}_{18}$ column; $50 \times 3.0 \mathrm{~mm}$; particle size, $2.7 \mu \mathrm{m}$ ) was used for appropriate chromatographic separation. The isocratic elution of the mobile phase was accomplished with $5 \mathrm{mM}$ formic acid in water and acetonitrile at a ratio of $84: 16(\mathrm{v} / \mathrm{v})$ and a flow rate of $0.3 \mathrm{~mL} / \mathrm{min}$. To minimize contamination of the ESI source and mass spectrometer, the eluent was switched to a waste line during the first minute. The total run time was $3.5 \mathrm{~min}$. The column and autosampler temperatures were set at 30 and $4{ }^{\circ} \mathrm{C}$, respectively.

The column eluent was monitored using a triple quadrupole tandem mass spectrometer equipped with an ESI source in positive ion mode. The instrumental conditions were as follows: gas temperature $\left(350{ }^{\circ} \mathrm{C}\right)$, sheath gas temperature $\left(400{ }^{\circ} \mathrm{C}\right)$, gas flow $(13 \mathrm{~L} / \mathrm{min})$, sheath gas flow (12 L/min), nebulizer (55 psi), and electrospray voltage $(3.5 \mathrm{kV})$. The fragmentor voltages for both DA-7010 and the IS were set at $80 \mathrm{~V}$. The collision energies for DA-7010 and the IS were 13 and $15 \mathrm{eV}$, respectively. The precursor $\left([\mathrm{M}+\mathrm{H}]^{+}\right)$-toproduct ion transitions used for quantification were $m / z 220.1 \rightarrow 162.1$ for DA-7010 and $\mathrm{m} / \mathrm{z}$ $206.1 \rightarrow 170.1$ for the IS.

\subsection{Preparation of Calibration Standards and QC Samples}

Standard stock solutions of DA-7010 and the IS were prepared by dissolving each drug in methanol to yield a nominal concentration of $1 \mathrm{mg} / \mathrm{mL}$. Standard working solutions of DA-7010 were prepared by appropriate dilutions of the stock solutions with methanol $(1-1000 \mu \mathrm{g} / \mathrm{mL})$. The IS working solution was prepared at a concentration of $10 \mu \mathrm{g} / \mathrm{mL}$ from stock solution using methanol for dilution.

Each working stock solution of DA-7010 $(10 \mu \mathrm{L})$ was spiked into pooled, drug-free mouse, rat, or dog plasma $(1000 \mu \mathrm{L})$ at final concentrations of $10,25,50,250,1000$, and $10,000 \mathrm{ng} / \mathrm{mL}$ to prepare the calibration samples. The QC samples were prepared at final concentrations of 10 (LLOQ), 30 (low QC), 400 (medium QC), and 8000 (high QC) ng/mL in the same manner as the calibration samples by separately weighing the DA-7010. All the stock solutions and calibration and QC samples were immediately stored at $-20{ }^{\circ} \mathrm{C}$ and brought to room temperature prior to use. 


\subsection{Sample Preparation}

A $100 \mu \mathrm{L}$ aliquot of the IS working solution $(10 \mu \mathrm{g} / \mathrm{mL}$ in methanol) was added to each $25 \mu \mathrm{L}$ plasma sample and mixed by vortexing to precipitate the protein. After centrifugation ( $16,000 g, 5 \mathrm{~min})$, the supernatant was transferred to an $\mathrm{LC}$ vial, and a $2 \mu \mathrm{L}$ aliquot was injected into the LC column for analysis.

\subsection{Validation of Analytical Method}

The developed method has been validated according to the US FDA guidelines for the validation of bioanalytical methods [12] for selectivity, carryover, linearity, sensitivity, precision, accuracy, recovery, the matrix effect, and stability.

\subsubsection{Selectivity, Carryover, Linearity, and Sensitivity}

To assess the selectivity of the method, 6 different sources of drug-free plasma from mice, rats, and dogs were analyzed for the presence of interfering peaks in the retention times of the analyte and the IS. To evaluate the carryover, a blank plasma sample was analyzed after injecting a high QC sample. The linearity was assessed based on calibration curves with 6 levels of the analyte as described in Section 3.3. The calibration curves were constructed using weighted $\left(1 / \mathrm{x}\right.$ or $\left.1 / \mathrm{x}^{2}\right)$ least-squares linear regression of the plot for the peak area ratio of DA-7010 to the IS (y) versus the relative concentration of DA-7010 to the IS (x). The analytical sensitivity was assessed by the LLOQ, which was defined as the lowest quantifiable level (signal-to-noise ratio $>10$ ) with acceptable precision $(\mathrm{RSD}<20 \%)$ and accuracy (80-120\%).

\subsubsection{Precision and Accuracy}

To determine the intraday precision and accuracy, 5 replicates of LLOQ, low, medium, and high QC samples were analyzed in a single run. The precision and accuracy for the interday analyses were assessed by analyzing QC samples at 4 levels for 5 consecutive days (more than 3 repetitions each time). The precision is expressed as the RSD (\%), and the accuracy was calculated as (determined concentration/nominal concentration) $\times 100 \%$. The acceptance criterion for the precision was set to RSD $<15 \%$ ( $<20 \%$ for LLOQ), and that for the accuracy was $85-115 \%$ ( $80-120 \%$ for the LLOQ).

\subsubsection{Recovery and Matrix Effect}

For the measurement of the recovery and matrix effects, $3 \mathrm{QC}$ analyte levels and the IS were used. The peak areas of the analyte or IS in the extracted QC samples (spiked prior to extraction) were compared with those in the spiked samples (spiked into post-extracted blank plasma) with corresponding concentrations to determine the extraction recovery. The matrix effect was determined by comparing the peak areas of the analyte or IS from the spiked, post-extracted, blank plasma (with matrix) with those of the samples spiked with post-extracted water (without matrix).

\subsubsection{Stability of the Analyte}

The stability of DA-7010 in the plasma from the mice, rats, and dogs was evaluated by analyzing 3 replicates of low, medium, and high QC samples under various storage conditions: the bench-top short-term stability (at room temperature for $8 \mathrm{~h}$ ), postpreparative stability (prepared samples kept in LC vials at $4{ }^{\circ} \mathrm{C}$ for $24 \mathrm{~h}$ ), freeze-thaw stability ( 3 freeze/thaw $\left(-20^{\circ} \mathrm{C} /\right.$ room temperature) cycles), and long-term freezing stability $\left(-20^{\circ} \mathrm{C}\right.$ for 1 month). The analyte was determined to be stable when the estimated recovery (determined concentration/nominal concentration $\times 100 \%$ ) was in the range of $85-115 \%$ and the RSD was $<15 \%$.

\subsection{Pharmacokinetic Studies of DA-7010 in Mice, Rats, and Dogs}

The validated method was applied to pharmacokinetic studies of DA-7010 in mice, rats, and dogs. The protocols for the animal study were approved by the Department 
of Laboratory Animals, Institutional Animal Care and Use Committee (IACUC), on the Sungsim Campus of the Catholic University of Korea (approval no. 2014-022) or by IACUC of Biotoxtech (Cheongju, South Korea) (approval no. 140765). Male ICR mice and SpragueDawley rats ( 8 weeks old) were purchased from Samtaco Bio (Osan, South Korea). Male beagle dogs ( 10 months old), which are products from Beijing Marshall Biotechnology (Beijing, China), were used for this study. The accommodation and handling procedures for the animals were similar to those previously reported $[13,14]$. Prior to dosing, the animals were fasted for $15 \mathrm{~h}$ and allowed to drink water freely. DA-7010 hydrochloride was administered in the pharmacokinetic study, and the dose of DA-7010 described below is based on the free base form of DA-7010.

DA-7010 (dissolved in distilled water) at a dose of $3 \mathrm{mg}$ (in $10 \mathrm{~mL}$ ) per kilogram was administered orally to the mouse groups $\mathrm{A}$ and $\mathrm{B}(n=6$ each) using gastric gavage. Blood samples $(\sim 50 \mu \mathrm{L})$ were collected into separate heparinized capillary tubes from the retroorbital plexuses of mice that were under light anesthesia, which was achieved by isoflurane inhalation at 5, 30, 120, and $480 \mathrm{~min}$ for group A and 15, 60, 240, and 600 min for group $\mathrm{B}$ following the oral administration of DA-7010. The collected sample was immediately centrifuged, and a $25 \mu \mathrm{L}$ plasma sample was stored at $-20{ }^{\circ} \mathrm{C}$ until it was used for the LC-MS/MS analyses of DA-7010.

For the rat, the carotid artery was cannulated for serial blood sampling [14]. DA-7010 (dissolved in distilled water) at a dose of $3 \mathrm{mg}$ (in $2 \mathrm{~mL}$ ) per kilogram was administered orally to the rats $(n=7)$ using gastric gavage. Blood samples $(\sim 50 \mu \mathrm{L})$ were collected at $0,5,10,20,30,60,120,240,360,480$, and $720 \mathrm{~min}$ via the carotid artery following the oral administration of the drug. The cannula was flushed immediately after each blood sampling to prevent blood clotting using a $0.3 \mathrm{~mL}$ heparinized $0.9 \% \mathrm{NaCl}$-injectable solution ( 20 units $/ \mathrm{mL}$ ). The same procedure described above was used for the collection and storage of the plasma samples.

For the oral administration of DA-7010 in dogs, $3 \mathrm{mg} / \mathrm{kg}$ DA-7010 was loaded in a gelatin capsule (size 12, Torpac Inc., Fairfield, NJ, USA) without other excipients. Approximately $2 \mathrm{~mL}$ of blood was collected via the cephalic vein using a heparinized $(100 \mathrm{IU} / \mathrm{mL})$ $23 \mathrm{G}$ syringe at pre-dose and 15, 30, 45, 60, 120, 240, 360, 480, 720, and $1440 \mathrm{~min}$ after the administration of the drug. The collection and storage of each plasma sample $(25 \mu \mathrm{L})$ and extra plasma sample were performed using the same procedure described above.

The pharmacokinetic parameters were calculated using noncompartmental analyses (WinNonlin; Pharsight Corporation, Mountain View, CA, USA) [15]. The AUC $0-\infty$ was calculated using the trapezoidal rule-extrapolation method [16]. The $C_{\max }$ and $T_{\max }$ were read directly from the experimental data.

\section{Conclusions}

The fast and simple LC-MS/MS method developed in this study enables the robust and sensitive quantification of DA-7010 in plasma from mice, rats, and dogs. This method has proven to be accurate, precise, and highly efficient by avoiding the plasma matrix effects of various species and enabling the reproducible recovery of the analyte through simple protein precipitation. The method was successfully applied to pharmacokinetic studies of DA-7010 in these preclinical species following the oral administration of DA-7010. The oral absorption of DA-7010 was rapid, and the systemic exposure was approximately four times higher in dogs than in mice or rats. This is the first reported pharmacokinetic study of DA-7010, a new antibacterial drug candidate for Gram-negative pathogens. The analytical method and pharmacokinetic data presented in this study can be applied in further preclinical pharmacokinetic studies of DA-7010.

Supplementary Materials: The following are available online at https://www.mdpi.com/1424-8 247/14/2/163/s1. Figure S1: HR-MS (A) and ${ }^{1} \mathrm{H}-\mathrm{NMR}$ (B) spectra of DA-7010, Figure S2: Fullscan mass spectra of DA-7010 (A) and the IS (B), Figure S3: Representative calibration curves with regression equations for DA-7010 in plasma from various species (mice (A), rats (B), and dogs (C)). 
Author Contributions: Conceptualization, D.Y.L. and H.E.K.; methodology and investigation, M.H.K. and H.E.K.; resources, D.Y.L.; data curation, H.E.K.; writing—original draft preparation, M.H.K.; writing—review and editing, D.Y.L. and H.E.K.; funding acquisition, H.E.K. All authors have read and agreed to the published version of the manuscript.

Funding: This research was supported by Dong-A ST Co., Ltd., partly by a National Research Foundation of Korea (NRF) grant funded by the Korean government (No. 2018R1A6A1A03025108 (Ministry of Education) and 2019R1F1A1052243 (MSIT)), and by the Research Fund, 2020, of The Catholic University of Korea.

Institutional Review Board Statement: The animal study protocols have been reviewed by IACUC and are stated in Section 3.6 with the respective approval no.

Data Availability Statement: The main part of the research data is contained in the article and Supplementary Materials. Other data including chromatograms are available from the corresponding author upon request.

Conflicts of Interest: The authors declare no conflict of interest. The funders had no role in the design of the study; in the collection, analyses, or interpretation of data; in the writing of the manuscript; or in the decision to publish the results.

\section{References}

1. Peleg, A.Y.; Hooper, D.C. Hospital-acquired infections due to Gram-negative bacteria. N. Engl. J. Med. 2010, 362, 1804-1813. [CrossRef] [PubMed]

2. $\quad$ Park, J.S.; IM, W.B.; Choi, S.H.; Sung, H.J.; Lee, H.K.; Moon, J.H.; Lee, M.J.; Choi, J.H. In Proceedings of the In Vitro Antibacterial Activity and In Vivo Efficacy of DA-7010 against Gram-Negative Pathogens; A Novel Bacterial Leucyl-tRNA Synthetase Inhibitor. 27th ECCMID, Vienna, Austria, 24 April 2017; (Poster number P1371A). Available online: https://www.escmid.org/escmid_ publications / escmid_elibrary/material/?mid=51918 (accessed on 21 January 2021).

3. Park, J.S.; IM, W.B.; Choi, S.H.; Sung, H.J.; Moon, J.H.; Choi, J.H. In Proceedings of the 27th ECCMID Discovery and SAR of Potent Antibacterial Agents as Leucyl t-RNA Synthetase Inhibitors with Potential Activity against Gram-Negative Bacteria, Vienna, Austria, 24 April 2017; (Poster number P1371). Available online: https:/ /www.escmid.org/escmid_publications/escmid_ elibrary / material/?mid=51917 (accessed on 21 January 2021).

4. Nocentini, A.; Supuran, C.T.; Winum, J.-Y. Benzoxaborole compounds for therapeutic uses: A patent review (2010-2018). Expert Opin. Ther. Patents 2018, 28, 493-504. [CrossRef]

5. Si, Y.; Basak, S.; Li, Y.; Merino, J.; Iuliano, J.N.; Walker, S.G.; Tonge, P.J. Antibacterial activity and mode of action of a sulfonamidebased class of oxaborole leucyl-tRNA-synthetase inhibitors. ACS Infect. Dis. 2019, 5, 1231-1238. [CrossRef] [PubMed]

6. Zhang, P.; Ma, S. Recent development of leucyl-tRNA synthetase inhibitors as antimicrobial agents. Med. Chem. Commun. 2019, 10, 1329-1341. [CrossRef]

7. Lee, E.-Y.; Kim, S.; Kim, M.H. Aminoacyl-tRNA synthetases, therapeutic targets for infectious diseases. Biochem. Pharmacol. 2018, 154, 424-434. [CrossRef]

8. Nie, A.; Sun, B.; Fu, Z.; Yu, D. Roles of aminoacyl-tRNA synthetases in immune regulation and immune diseases. Cell Death Dis. 2019, 10, 1-14. [CrossRef] [PubMed]

9. Francklyn, C.S.; Mullen, P. Progress and challenges in aminoacyl-tRNA synthetase-based therapeutics. J. Biol. Chem. 2019, 294, 5365-5385. [CrossRef] [PubMed]

10. Kim, S.-H.; Bae, S.; Song, M. Recent development of aminoacyl-tRNA synthetase inhibitors for human diseases: A future perspective. Biomolecules 2020, 10, 1625. [CrossRef] [PubMed]

11. Zhou, Z.; Sun, B.; Nie, A.; Yu, D.; Bian, M. Roles of aminoacyl-tRNA synthetases in cancer. Front. Cell Dev. Biol. $2020,8,599765$. [CrossRef] [PubMed]

12. Bioanalytical Method Validation Guidance for Industry. US FDA/Center for Drug Evaluation and Research. 2018. Available online: https: / / www.fda.gov/media/70858/download (accessed on 21 January 2021).

13. Jung, J.W.; Kim, J.M.; Kwon, M.H.; Kim, D.H.; Kang, H.E. Pharmacokinetics of macrolactin A and 7-O-succinyl macrolactin A in mice. Xenobiotica 2013, 44, 547-554. [CrossRef] [PubMed]

14. Kang, H.E.; Jung, H.Y.; Cho, Y.K.; Kim, S.H.; Sohn, S.I.; Baek, S.R.; Lee, M.G. Pharmacokinetics of liquiritigenin in mice, rats, rabbits, and dogs, and animal scale-up. J. Pharm. Sci. 2009, 98, 4327-4342. [CrossRef] [PubMed]

15. Gibaldi, M.; Perrier, D. Pharmacokinetics, 2nd ed.; Marcel-Dekker: New York, NY, USA, 1982.

16. Chiou, W.L. Critical evaluation of the potential error in pharmacokinetic studies of using the linear trapezoidal rule method for the calculation of the area under the plasma level-time curve. J. Pharmacokinet. Biopharm. 1978, 6, 539-546. [CrossRef] [PubMed] 